\title{
O que há de especificamente comunicacional na religião?
}

\author{
What's specifically communicational in religion? \\ ¿Qué es específicamente comunicacional en la religión? \\ Herivelton Regiani ${ }^{1}$ \\ Viviane Borelli ${ }^{2}$
}

\begin{abstract}
Resumo
A partir de distintas abordagens do fenômeno religioso pelas ciências sociais e humanas, indaga-se sobre a contribuição específica do olhar comunicacional sobre o campo religioso. Em função do papel preponderante que a mídia exerce recentemente, considera-se que o conceito de midiatização possibilita uma aproximação teórica e metodológica entre esses campos. Para problematizar a religião como objeto de estudo específico para o campo científico da comunicação, faz-se uma revisão bibliográfica para discutir alguns conceitos centrais para o estudo: objeto da comunicação, campos e midiatização. A reflexão aponta que o olhar comunicacional sobre o objeto religioso incide especificamente sobre os aspectos que evidenciam o processo de midiatização da religião.
\end{abstract}

Palavras-chave: Religião. Comunicação. Midiatização. Campos sociais.

\begin{abstract}
From different approaches of the religious phenomenon in the social sciences and humanities, inquiries are made about the specific contribution of the communication gaze on the religious field. Due to the important role that the media plays in our days, it is consider that the concept of mediatization makes possible a theoretical and methodological approach in between these fields. To question religion as a specific object of study for the scientific field of communication, it is necessary to make a bibliographical review to discuss some central concepts of the research: Communication object, fields and media coverage. The reflexion indicates that the communicational look upon the religion object specifically focuses on the aspects that evidence the mediatization process of religion.
\end{abstract}

Keywords: Religion. Communication. Mediatization. Social fields.

\section{Resumen}

A partir de diferentes enfoques del fenómeno religioso en las ciencias sociales y las humanidades, nos preguntamos acerca de la contribución específica de la mirada comunicacional en el campo religioso. Debido al importante papel desempeñado por los medios recientemente, se considera que el concepto de mediatización ofrece un enfoque teórico y metodológico entre estos campos. Para cuestionar la religión como un objeto de estudio específico para el campo científico de la comunicación, se hace una revisión de la

\begin{tabular}{|c|c|}
\hline & Acesse este artigo online \\
\hline \multirow{2}{*}{ 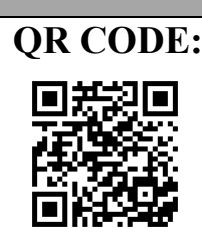 } & $\begin{array}{l}\text { Website: } \\
\text { http://www.revistas.ufg.br/index.php/ci }\end{array}$ \\
\hline & $\begin{array}{l}\text { DOI: } \\
\text { http://dx.doi.org/10.5216/ci.v19i2.3684 } \\
6\end{array}$ \\
\hline
\end{tabular}
literatura para discutir algunos conceptos centrales para el estudio: la comunicación, los campos sociales y la

mediatización. La reflexión muestra que el enfoque comunicacional al objeto religioso se centra específicamente en los aspectos que demuestran el proceso de mediatización de la religión.

\footnotetext{
${ }^{1}$ Mestrando do Programa de Pós-graduação em Comunicação da Universidade Federal de Santa Maria, RS. Brasil, Santa Catarina. E-mail: heriveltonreg@gmail.com

${ }^{2}$ Doutora em Ciências da Comunicação pela Unisinos. Professora do Programa de Pós-Graduação da Universidade Federal de Santa Maria. Brasil, Santa Catarina: E-mail: borelliviviane@gmail.com
}

Comun. \& Inf., Goiânia, GO, v. 19, n. 2, p. 71-85, jul./dez. 2016. 
Palabras clave: Religión. Cominicación. Mediatización. Campos Sociales.

\section{INTRODUÇÃO}

religião, em sua relação com a sociedade e a cultura, é estudada de diferentes
pontos de vista. São vários os ângulos e olhares possíveis segundo as ciências
sociais e humanas. Há também na área da Comunicação uma profusão considerável de estudos envolvendo a religião. Mas o que faz com que determinado fenômeno religioso seja considerado objeto de estudo na área comunicacional? De que modo diferente nosso olhar incide (ou deveria incidir) sobre esse fenômeno, se comparado ao que já oferecem as demais ciências?

Para além da necessidade de conhecer estudos que trabalhem com a interface entre comunicação e religião em função da proposta de pesquisa de Mestrado, motivou-nos a fazer essa reflexão, o questionamento de Luiz Signates (2013) acerca do "que é especialmente comunicacional nos estudos brasileiros de comunicação da atualidade". Como decorrência deste questionamento, e da forma como o autor e outros estudiosos o respondem, passamos a refletir sobre a necessidade de pensar sobre o que torna especificamente comunicacional um estudo voltado para fenômenos do campo religioso. Isso porque nos interessa particularmente a interface entre esta dimensão da experiência humana e a comunicação, em sua história e, sobretudo, na atualidade, marcada pela presença e atuação forte das mídias em relação aos campos sociais, a sociedade e os sujeitos.

Propomos aqui um percurso em grande medida exploratório, mas possivelmente propositivo. O trajeto parte da pergunta de Signates (2013) para contextualizar a importância da definição do lugar ou do campo específico da comunicação entre as ciências humanas e sociais. Na problematização deste campo e das interfaces com outros saberes, ou dos entrecruzamentos com outros campos, são importantes as indicações levantadas por Braga (2011), França (2001), Martino (2001) e Rodrigues (1999).

No caso deste último, se descortina o pano de fundo para um outro passo: pensar a midiatização pensar a midiatização como o conceito que descortina o que há de mais relevante, na atualidade, no que concerne à religião como questão comunicacional. Rodrigues (1999) não utiliza o termo midiatização, mas descreve o processo de autonomização dos campos, que de certo modo, levou até a modernidade ou modernidade tardia, com suas consequências também para o campo das mídias e o campo religioso. Para a compreensão do conceito de midiatização, recorreremos às contribuições de Verón (2014) e Fausto Neto (2008) e, finalmente, à perspectiva de Braga (2006)

Comun. \& Inf., Goiânia, GO, v. 19, n. 2, p. 71-85, jul./dez. 2016. 
sobre a midiatização como um processo interacional de referência. Nosso objetivo é mostrar como a midiatização é processo de referência para um enfoque verdadeiramente comunicacional sobre fenômenos do campo religioso.

Para isso, inicialmente discutimos o que é o específico da comunicação na abordagem dos fenômenos sociais e, em particular, no estudo da religião como objeto. Na segunda parte, revisitamos o conceito de campos sociais e sobre o processo que deu origem à comunicação como um campo autônomo, e no qual se estabeleceu uma relação especial do campo comunicacional com os demais campos, inclusive o da religião. Em seguida, na terceira parte, chegamos ao conceito de midiatização e destacamos como o mesmo fornece os elementos que possibilitam, na atualidade, uma abordagem propriamente comunicacional da religião. Por último, fazemos apontamentos, considerações e indicações a partir do que evidenciamos.

\section{O ESPECÍFICO DA COMUNICAÇÃO E A RELIGIÃO COMO OBJETO}

Para se estabelecer, toda ciência precisa reivindicar o que lhe é específico. Porém, num movimento natural, toma como ponto de partida conceitos e pesquisas realizadas em outras ciências e aquilo que, a partir delas, surgiu como novo e criou a necessidade de outros instrumentos e perspectivas para ser compreendido. Mas a comunicação é um campo do saber tão ligado aos seus precursores nas ciências humanas que, por vezes, dificulta seu reconhecimento como um campo independente.

Ao levantar esta possível fragilidade epistemológica do campo da comunicação, Signates (2013) ressalta que há, pelo menos no Brasil, um campo científico da comunicação. Um campo com instituições, pesquisadores, programas de estudo e formação específica. No entanto, boa parte dos estudos em comunicação têm se fundamentado em disciplinas científicas já antes consagradas, mas que "não levam em consideração o objeto específico da comunicação" (SIGNATES (2013, p.19). Para ele, boa parte das pesquisas tocam na comunicação e a relacionam a outros fenômenos sociais, mas a comunicação não tem papel central nesses estudos.

$\mathrm{O}$ autor ainda afirma que, na resposta à singularidade epistemológica da comunicação, não basta dizer que o objeto da comunicação é múltiplo ou multifacetado, pois seria uma assertiva vazia. Seria o mesmo que dizer que não há objeto ou uma unidade básica. "Compreende-se que a diversidade faz parte do modo de ser do conhecimento, em qualquer área da ciência ou da filosofia; [...] Contudo, uma ciência que se pretenda legítima deve manter alguma unidade na abordagem do objeto que a define" (SIGNATES, 2013, p.20). 
O autor também concebe que não se resolve a questão ao constatar que se trata de um campo ainda jovem e em formação. Para sua constituição, avalia Signates (2013), qualquer ciência precisa de um objeto claramente definido, com vistas as quais irão configurar sua teoria e métodos.

Um dos motivos para a dificuldade de compreensão do que é objeto específico da comunicação pode ser a noção, conhecida no senso comum, de que tudo é comunicação e a comunicação está em tudo. O senso comum pode ter, e frequentemente tem, um fundo de realidade em que baseia suas crenças. Porém, se as ciências estabelecem-se ao desvincularem-se do senso comum e ao ultrapassarem as barreiras que ele impõe ao pensamento e à observação, o caminho para a comunicação é definir-se de forma que também ultrapasse essa concepção bela, porém estéril. Ou seja, o desafio é mostrar que o interesse realmente comunicacional não repousa sobre tudo, mas sobre um conjunto de questões bem específicas que só podem ser compreendidas pela abordagem que é própria desta área do conhecimento.

Embora haja um considerável interesse pela jovem disciplina que trata dos processos de comunicação, tanto Martino (2001) como Braga (2011) citam como verdadeira a consideração de Wilbur Schramm de que a Comunicação é uma encruzilhada pela qual muitos passam, porém onde poucos permanecem.

A natureza dos estudos das Ciências Humanas - que têm no homem, um ser especialmente comunicativo, seu objeto comum - faz com que a análise dos processos comunicativos seja um ponto de passagem quase que obrigatório, o que dificulta a delimitação mais precisa do objeto da comunicação, uma vez que se encontra misturado às análises de outras disciplinas (MARTINO, 2001, p. 28).

Isso não ocorre porque os autores desmereçam o aspecto interdisciplinar que caracteriza a comunicação, mas porque salientam que esta ciência não pode ser uma "interseção passiva ou um simples efeito de diferentes orientações do saber" (MARTINO, 2001, p.29). A interdisciplinaridade própria da comunicação deve existir e ser articulada como consequência da compreensão de seu próprio objeto, não a partir de uma ausência dessa compreensão. Na concepção de Braga, a atenção às interfaces com outros saberes constitui "um verdadeiro e efetivo trabalho de interdisciplinaridade - desde que se leve a sério a busca dos enfoques comunicacionais" (BRAGA, 2011, p.64). Nesse sentido, o autor defende a efetiva explicitação de que tipo de interface há entre objetos de áreas de conhecimento distintas.

Para Martino (2001, p. 31), o objeto desta disciplina científica "não é todo e qualquer fenômeno comunicativo, mas apenas aqueles restritos à dimensão humana e mediatizados por dispositivos técnicos". Em outras palavras, para o autor, "trata-se de uma leitura do social realizada a partir dos meios de comunicação" (2001, p.31). Enquanto os meios de comunicação "atravessam

Comun. \& Inf., Goiânia, GO, v. 19, n. 2, p. 71-85, jul./dez. 2016. 
vários campos de saber, fica claro também que eles não constituem o objeto de nenhum saber em particular" (2001, p. 37) e, por isso, defende a necessidade de constituição de uma Ciência da Comunicação.

Braga (2011) considera que a comunicação pode estudar interações sociais que são tematizadas em outras disciplinas, mas problematizando-as de um ângulo comunicacional.

A diferença parece ser que em todas as demais áreas observa-se a comunicação enquanto processo que faz funcionar alguma outra atividade ou instância de interesse social-humano - a literatura, a linguagem, a política, as trocas econômicas, etc. No campo específico da Comunicação, inversamente, os diferentes objetivos e objetos do humano e do social é que seriam percebidos pelo ângulo prioritário da comunicação que os organiza e que deles decorre (BRAGA, 2011, p.67).

Entretanto, mesmo reconhecendo a forte preocupação com os processos midiáticos, o autor ressalta que a opção simples pelos meios de comunicação como o objeto poderia levar a uma redução centrada apenas nas questões tecnológicas ou concernentes à constituição das mídias, deixando escapar outras questões importantes da interação social. O autor ainda diz que se interessa pelo conceito de midiatização como um processo comunicacional do que pelas mídias como objeto da comunicação. Isto porque o conceito "enfatiza expressamente processos segundo os quais 'as mídias funcionam', mas também pelos quais a sociedade contemporânea historicamente aciona suas interações” (BRAGA, 2011, p.67). Essa questão será melhor discutida adiante.

Embora com algumas diferenças, os autores apontam para a necessidade de uma abordagem que tome a comunicação como o ângulo central e não como mais um fenômeno entre outros ou como instrumental para compreensão de outro objeto. $\mathrm{O}$ olhar da comunicação sobre fenômenos constituintes de outros campos sociais, e que sejam tocados por outros campos científicos, se diferencia por centrar-se na interação comunicacional como modo de compreender o social. Esse olhar pode ter em foco os meios de comunicação em suas especificidades ou o processo pelo qual eles passam a constituir e organizar a própria sociedade.

Esta noção será especialmente útil na compreensão do aspecto que aqui buscamos, o que há de propriamente comunicacional na religião, pois conceituando melhor o que pertence aos estudos comunicacionais na sociedade, acabamos por encontrar as pistas para o que concerne à comunicação no estudo dos fenômenos religiosos.

Uma breve visada sobre a história do surgimento da comunicação como ângulo específico e da sua constituição como campo autônomo auxiliará a compreender e reforçar essa perspectiva, ao 
mesmo tempo em que nos levará ao que é próprio da comunicação no campo religioso na atualidade.

\section{A COMUNICAÇÃO E OS CAMPOS SOCIAIS}

Em uma perspectiva histórica, o saber que se constrói como campo científico da comunicação ganha importância na organização coletiva advinda da modernidade. Trata-se de uma sociedade que já não se fundamenta sobre a tradição, mas sobre uma busca constante de atualidade, e a comunicação através dos meios passa a ter papel central na "representação da totalidade social" e nas "estratégias de engajamento do indivíduo" (MARTINO, 2011, p.34).

Nesse sentido, encontramos uma importante descrição nas palavras de França (2001) para quem, embora os processos comunicacionais sempre tenham existido, é na modernidade que eles se tornam questão digna de uma nova ciência:

Quando a modernidade (rompendo com o mundo da tradição e com a legitimidade prévia de uns poucos locutores autorizados) traz o homem ao centro do palco [...] esse novo sujeito de poder, nessa nova experiência no mundo, se vê às voltas com seu instrumento primordial, que é a palavra. A palavra a ser dita, a palavra a ser escutada, a palavra em busca de sua legitimação, a palavra que se prolifera... A modernidade transformou a comunicação em problema; levantou questões em torno de uma prática até então natural, naturalizada - prática esta que desde então se impôs aos homens como algo a ser melhor conhecido. (FRANÇA, 2001, p.46)

Fazendo uma digressão à origem das três grandes religiões que influenciaram o ocidente, tanto no Judaísmo, como no Cristianismo e no Islamismo, a palavra sempre ocupou uma posição central. São religiões centradas em livros sagrados, a Torá, o Novo Testamento e o Corão, que se relacionam e que, apesar das diferenças, reivindicam uma mesma fonte, a palavra divina revelada, têm muitas histórias e ensinamentos em comum. Como afirma Armstrong (1994, p.13), “o deus dos judeus, cristãos e muçulmanos é um Deus que - em algum sentido - fala. Sua Palavra é crucial em todas as três. A Palavra de Deus moldou a história de nossa cultura".

$\mathrm{Na}$ modernidade, essa relação com a palavra se problematiza, e a comunicação se coloca como questão para a sociedade e os campos que a constituem. O discurso é que garante a mediação entre os distintos campos sociais e cabe ao campo midiático construir essa simbólica por meio da linguagem, como lembra Rodrigues (1999). Da mesma forma, a comunicação da palavra, tão cara ao campo religioso também passa por tensões e transformações em sua interação com os demais campos, incluindo o midiático.

Comun. \& Inf., Goiânia, GO, v. 19, n. 2, p. 71-85, jul./dez. 2016. 
O movimento que coloca a comunicação como problemática científica, se dá justamente no contexto de uma mudança na relação da sociedade com a religião. A palavra, antes legitimada pela religião como de procedência divina, passa a ser questionada, em uma relação complexa na qual mesmo o indivíduo religioso se vê imerso em ambientes de múltiplas palavras, que disputam certo poder sobe sua consciência e seus modos de vida. É um processo descrito por Weber (1996) como desencantamento do mundo: uma racionalização crescente da sociedade, também denominada secularização. A partir da secularização é que a religião, antes tomada como a unificadora da experiência humana e dotadora de sentido e segurança às demais práticas, deixa de ser o centro, e passa a se tornar apenas um entre outros campos sociais.

Rodrigues (1999) descreve esse movimento como uma dessacralização da experiência do mundo, um processo de autonomização das dimensões da experiência. Os discursos e as práticas sociais que antes eram naturalizadas pela tradição e pela religião e passam a ter a necessidade de serem refletidas e legitimadas. Para o autor, ao invés de um apelo à tradição que podia ser traduzido pela transmissão de valores e crenças herdadas historicamente, "a modernidade apela para um tipo diferente de racionalidade, para uma indagação racional, metodicamente conduzida, dos fenómenos inerentes tanto ao domínio da experiência de si, como aos domínios do mundo natural e dos outros" (RODRIGUES, 1999, p.12).

O autor concebe que é esse tipo de racionalidade que vai orientar e diferenciar os domínios e dimensões da experiência, conduzindo a um processo de autonomização e institucionalização dos diferentes campos sociais. Esse processo está ligado à constituição do sujeito e sua emancipação em relação às imposições da tradição, fortemente ligadas à religião e por ela legitimadas.

São mudanças sociais que incidem, portanto, sobre o prório campo religioso e sobre as demais dimensões da esperiência humana, fazendo com que, em cada uma delas, seja necessária a configuração de novas estratégias na busca por legitimidade e representatividade diante da complexificação e racionalização de toda a vida social.

A autonomização moderna dos diferentes domínios e das diferentes dimensões da experiência é um processo eminentemente secularizante, na medida em que a religião deixa de ser o quadro unificador e homogeneizador da totalidade da experiência" (RODRIGUES, 1999, p.17).

A racionalidade metódica que está na base dessa mudança conduzirá à diferenciação, autonomização e à progressiva institucionalização dos campos sociais. À medida que cada um dos domínios da experiência vai se autonomizando, estes passam a se constituir em campos dotados de "legitimidade para criar, impor, manter, sancionar e restabelecer os valores e as regras, tanto

Comun. \& Inf., Goiânia, GO, v. 19, n. 2, p. 71-85, jul./dez. 2016. 
constitutivas como normativas, que regulam um domínio autonomizado da experiência" (RODRIGUES, 1999, p.17 e 18).

Campos são entendidos pelo autor como "domínios autónomos da experiência intersubjectiva" (RODRIGUES, 1999, p.16). O conceito não se refere a uma unidade espacial ou geográfica, pois se trata de uma metáfora trazida da física para designar uma tensão entre forças (um campo de forças). Cada campo social tem "a pretensão de regular um determinado domínio da experiência, a partir da delimitação de um determinado quadro do sentido" (p.18). ${ }^{3}$

Por campo social entendo uma instituição dotada de legitimidade indiscutível, publicamente reconhecida e respeitada pelo conjunto da sociedade, para criar, impor, manter, sancionar e restabelecer uma hierarquia de valores, assim como um conjunto de regras adequadas ao respeito desses valores num determinado domínio específico da experiência (RODRIGUES, 1999, p.19).

Os campos sociais funcionam como "campos de legitimidade". Cada um deles toca aos demais em alguns entrecruzamentos, e na fronteira entre eles há uma luta pela "mobilização do conjunto da experiência” (RODRIGUES, 1999, p.18). Assim, a respeito de questões sociais há disputas entre os campos político, o médico, o jurídico e o religioso pela autoridade para falar sobre esses temas, como do aborto, por exemplo. Ou seja, cada campo produz seus próprios fundamentos para legitimar o que avalia ser o melhor para ser dito acerca de determinadas temáticas a partir de seu conhecimento específico.

Rodrigues ainda descreve o período em que vivemos, já em estado avançado nesse processo, como sendo especialmente "a época da autonomização do campo dos media" (RODRIGUES, 1999, p.2). Essa autonomização se dá de tal forma que o campo midiático ${ }^{4}$ passa a se constituir não somente como o mediador entre os demais campos, conferindo-lhes voz e visibilidade diante do conjunto da sociedade, mas também como mobilizador em torno de questões às quais os diversos campos deverão, à sua maneira e em seu domínio específico, responder. Cabe ao campo midiático refletir e problematizar questões sociais que não são indiscutivelmente solucionadas por nenhum dos campos sociais de maneira isolada, questões estas que ele faz emergir da fronteira entre esses campos (a droga, a sexualidade, o aborto, a ecologia são alguns exemplos).

Nesse processo, como detalha Rodrigues (1999) cada um dos demais campos deve se adequar aos valores, regras e sanções próprias do midiático, sob pena de não conquistar a desejada

\footnotetext{
${ }^{3}$ Importante ressaltar aqui a existência de diferentes conceitos de campo, e notadamente o de Bourdieu (2012). O conceito destacado neste trabalho é escolhido devido à sua importante relação com a compreensão da gênese do campo da comunicação e suas relações com os demais campos.

${ }^{4}$ Mesmo que o autor utilize a expressão "dos media", optamos fazer uso do termo em português: midiático e campo das mídias.
}

Comun. \& Inf., Goiânia, GO, v. 19, n. 2, p. 71-85, jul./dez. 2016. 
visibilidade e a consequente legitimidade social. O campo das mídias pode ser um aliado dos demais campos ao mobilizar o conjunto social em torno de valores comuns, que permaneceriam fragmentados caso não houvesse sua gestão das relações entre os campos. De outro lado, impõe a eles os modos de funcionamento de seus discursos.

Observando a mudança ocorrida em relação à situação anterior, em que a tradição e as crenças religiosas desempenhavam um papel unificador e legitimador das práticas sociais, nota-se como o campo midiático passa a assumir, a partir da modernidade, embora não de maneira tão totalizante, um lugar de destaque e referência para os demais domínios da experiência. Como consequência religião, a quem antes pertencia em maior parte a representação da totalidade social, agora fica relegada a um entre os campos sociais que buscam essa representação através do campo midiático. Na sequência, refletimos sobre o modo como essa mudança vem se intensificando a ponto de constituir sociedades midiatizadas ou em vias de midiatização e, como se dá, nesse contexto, o processo de midiatização do campo religioso.

\section{MIDIATIZAÇÃO E CAMPO RELIGIOSO}

A teorização de Adriano Duarte Rodrigues (1999), da qual arrolamos apenas alguns pontos para melhor compreendermos nossa problemática, mostra um processo pelo qual passou grande parte das sociedades que se encontram no modelo da chamada modernidade. Neste estágio de desenvolvimento da sociedade, há uma configuração especial em que a mídia, suas lógicas e processos interacionais com os demais campos, detém lugar preponderante. O autor, na época em que tece suas considerações não leva a termo suas proposições a ponto de chegar a um conceito de sociedade midiatizada ou em vias de midiatização. Outros autores, posteriormente, dão o passo seguinte, como Eliseo Verón (2014), Antonio Fausto Neto (2008) e José Luiz Braga (2006), de cujos apontamentos nos valeremos nessa reflexão.

De início, é preciso ressaltar que para Verón (2014), a midiatização não é algo verificável apenas nas sociedades modernas, mas um processo resultante da própria capacidade humana de produção de semioses. A midiatização teve diferentes formas em processos históricos anteriores, mas aprofundou-se com a aceleração do tempo histórico que é própria da modernidade. A partir das proposições de Verón (2014), é compreendida como uma exteriorização dos processos mentais em dispositivos visuais e técnicos que vão da invenção de instrumentos de pedra às representações visuais rupestres e até a escrita e as tecnologias de comunicação mais contemporâneas.

Neste contexto, a midiatização é apenas o nome para a longa sequência histórica de fenômenos midiáticos sendo institucionalizados em sociedades humanas e suas múltiplas consequências. A vantagem conceitual da perspectiva de longo prazo é

Comun. \& Inf., Goiânia, GO, v. 19, n. 2, p. 71-85, jul./dez. 2016. 
nos relembrar que o que está acontecendo nas sociedades da modernidade tardia começou, de fato, há muito tempo. (VERÓN, 2014, p. 15 e 16)

Esse processo não se desenvolve de maneira linear, mas segundo padrões de aceleração que se situam em contextos específicos e segundo o surgimento de meios específicos. Em um movimento evolutivo, cada novo dispositivo técnico comunicacional gera efeitos que afetam em diferentes intensidades as sociedades. Verón (2014) cita como exemplo três períodos especiais em que considera ter havido uma aceleração do tempo histórico, reconhecendo que outros poderiam ser arrolados: as ferramentas de pedra do Alto Paleolítico; a invenção da prensa de tipos móveis no século XV; e nos últimos anos, a internet. Vivemos, portanto, um tempo acelerado em que a dinâmica da midiatização se mostra mais evidente e influente.

Já para Fausto Neto (2008), a midiatização é resultante da evolução de "processos midiáticos que se instauram nas sociedades industriais, tema eleito em reflexões analíticas de autores feitas nas últimas décadas e que chamam atenção para os modos de estruturação e funcionamento dos meios nas dinâmicas sociais e simbólicas (FAUSTO NETO, 2008, p.90).

Mesmo que situe a midiatização especificamente nas sociedades industriais, Fausto Neto (2008) tem em comum com o conceito de Verón (2014) a compreensão do que seja a dinâmica da midiatização:

Ocorre a disseminação de novos protocolos técnicos em toda extensão da organização social, e de intensificação de processos que vão transformando tecnologias em meios de produção, circulação e recepção de discursos. Já não se trata mais de reconhecer a centralidade dos meios na tarefa de organização de processos interacionais entre os campos sociais, mas de constatar que a constituição e o funcionamento da sociedade - de suas práticas, lógicas e esquemas de codificação - estão atravessados e permeados por pressupostos e lógicas do que se denominaria a "cultura da mídia" (FAUSTO NETO, 2008, p.92).

A diferença ou o passo adiante em relação à visão de Rodrigues (1999) sobre o papel do campo da mídia em relação aos demais está em que, para esses últimos autores, no contexto da midiatização a mídia não constitui apenas um campo auxiliar, mas determinante sobre as "práticas sociais, os processos interacionais e a própria organização social, se fazem tomando como referência o modo de existência desta cultura, suas lógicas e suas operações” (FAUSTO NETO, 2008, p.92). Assim, não cabe às mídias somente o papel mediador e regulador, e nem são instrumentos a serviço dos demais campos, pois adquirem um lugar central no modo de ser, fazer e de atribuir significados para os sujeitos e para a sociedade. 
Em linha semelhante, Braga (2006, p.10) propõe abordar a midiatização como "processo interacional em marcha acelerada", de tal forma que se torna um processo de referência, no sentido de considerar alguns processos como principais e com tendências de serem prevalecentes.

Os demais processos interacionais (que não sejam considerados "de referência") teriam estes como parâmetro, se refeririam a eles como critérios de validade e definidores de lógicas centrais. Um processo interacional "de referência", em um determinado âmbito, "dá o tom" aos processos subsumidos - que funcionam ou passam a funcionar segundo suas lógicas. Assim, dentro da lógica da mediatização, os processos sociais de interação mediatizada passam a incluir, a abranger os demais, que não desaparecem mas se ajustam (BRAGA, 2006, p. 11).

O autor desenvolve a teoria de que a sociedade se constrói de maneira diferente de acordo com os processos interacionais que toma como referência. Para ele, antes vivíamos em uma cultura da escrita; agora, em "uma crescente mediatização de base tecnológica" (BRAGA, 2006, p.13). Há uma tendência de que, nesse contexto atual, marcado pelo tecnológico, as interações sociais se tornem diferidas e difusas.

Em resumo, para Braga, no estágio atual da midiatização, não são apenas demarcados modos de organização e transmissão de mensagens; nem de produção de significados, mas sobretudo modos através dos quais a sociedade se constrói. "São padrões para 'ver as coisas', para 'articular pessoas' e mais ainda, relacionar sub-universos na sociedade e - por isso mesmo - modos de fazer as coisas através das interações que propiciam" (BRAGA, 2006, p.17).

Novamente, a midiatização ocupa lugar central para compreendermos a própria sociedade, um entendimento que se dá a partir da comunicação e tendo como referência objetos e conceitos próprios desta área do conhecimento. Compreensão que deve ser estendida aos diferentes campos sociais, entre eles, a religião. Merecem também estudos propriamente comunicacionais, entre outras, a midiatização da política, da ciência, da economia, da medicina.

Consideramos que é nesse sentido - mais do que qualquer abordagem de cunho sociológico, antropológico, histórico ou até psicológico - que a comunicação pode tomar como objeto de estudo a religião ${ }^{5}$. O alvo comunicacional é compreender os processos pelos quais, ao buscar legitimidade e visibilidade em um contexto social no qual não mais ocupa posição central, a religião se midiatiza.

Ou seja, na atualidade o que há de propriamente comunicacional na religião são as transformações e adequações pelas quais adota como referência, em seus processos de interação, as lógicas, os modos de dar significado e de fazer que são próprios do campo midiático. Ou ainda, em

\footnotetext{
${ }^{5}$ Nesse contexto, há uma série de pesquisas, como bem refere Martino (2014), que foram desenvolvidas a partir da intersecção entre os campos da comunicação e da religião.
}

Comun. \& Inf., Goiânia, GO, v. 19, n. 2, p. 71-85, jul./dez. 2016. 
que se modificam, a partir das tentativas de inserção das religiões no espaço das mídias, os modos de produção, circulação e recepção dos discursos que lhe são próprios.

A religião, em sua interação com os dispositivos midiáticos, subsistiu desde muito tempo em uma cultura literária. Particularmente no ocidente, as grandes religiões são marcadas pela centralidade dos livros sagrados. Não por acaso o primeiro livro a ser reproduzido na prensa de Gutemberg foi a Bíblia. Hoje, em um contexto atravessado por outros dispositivos tecnológicos, os atores do campo religioso procuram adaptar sua linguagem e produzir conteúdos sagrados em formatos para o rádio, a televisão, e mais recentemente, a internet. Isso implica não somente na transposição dos conteúdos e ritos para um outro meio, mas em adaptações na linguagem e nos discursos produzidos para que gerem determinados efeitos de sentidos por meio de distintos dispositivos midiáticos (BORELLI, 2010).

Mesmo quando não há intenção explícita, as produções discursivas religiosas para o campo midiático passam a se construir noutra lógica, segundo outras estratégias e visando novas dinâmicas de reconhecimento. Isso ocorre de modo que a mensagem de uma igreja para a televisão ou para a internet seja, de fato, outra mensagem, um discurso gerado para ser consumido por sujeitos espalhados nessa sociedade que é atravessada por múltiplas experiências, onde a mídia merece ser estudada (SILVERSTONE, 2002).

No contexto altamente diferenciado e difuso da internet e das plataformas de redes sociais, surgem, igualmente, outras maneiras de enunciar variadas formas de as religiões e seus líderes se relacionarem com os públicos fiéis ou prospectos, construindo-se outros contratos de leitura (VERÓN, 2004). Da mesma forma, os eventos, espaços de adoração e até mesmo o modo de apresentação ética e estética das figuras de liderança passam a se modificar para se adaptar às exigências do campo midiático.

\section{CONSIDERAÇÕES}

Ao longo da construção deste artigo, fomos percebendo que, para se refletir sobre como se podem desenvolver estudos propriamente comunicacionais de fenômenos do campo religioso precisaríamos rever o que há de especificamente comunicacional na sociedade, a partir de um olhar para seus diversos campos e o lugar do campo midiático. Nessa breve reflexão sobre o que constitui a sociedade humana na atualidade, ficou evidente que, mais do que uma ciência entre tantas que se dedicam ao ser humano, a comunicação trata de questões e lógicas sociais que são centrais na constituição do que chamamos de modernidade. 
É de certa forma irônico pensar que a comunicação adquiriu esta posição central de referência justamente quando a religião e a tradição deixaram de ocupá-la. A religião figura agora como um entre tantos outros campos autônomos da experiência. para sua sobrevivência e para a reafirmação de sua legitimidade em um mundo de tantas interações diferenciadas e difusas, passa a remodelar seus modos de dizer e fazer a partir da complexa relação com os demais campos e, particularmente, com o campo midiático.

Interessa especificamente investigar, portanto, do ponto de vista comunicacional, como a midiatização da religião ocorre nas suas diferentes manifestações e, igualmente, que tendências poderiam ser apontadas para o futuro do campo. Isto considerando-se que o campo religioso tem hoje uma relação muito mais complexa com os demais campos sociais e com as questões problematizadas com eles através da mídia. Sem falar das históricas disputas no interior do próprio campo religioso, com suas múltiplas vertentes e valores internos.

Como previmos, o percurso deste estudo nos levou a uma exploração marcadamente teórica, mas ao mesmo tempo nos permitiu a segurança de uma indicação propositiva: a de que o conceito de midiatização pode ser uma porta atual de entrada da comunicação para a compreensão do fenômeno religioso. Este é, evidentemente, um dos enfoques possíveis, mas um que, pelas reflexões realizadas, se mostra especialmente promissor.

Cabe, a partir desta constatação, empreender em seguida estudos mais específicos e de caráter empírico sobre como diversos indivíduos, grupos e instituições ligados à religião experimentam esse processo de midiatização em curso, bem como os modos como a partir dele agem, reagem e atuam estrategicamente segundo seus objetivos para se comunicarem.

A reflexão aqui desenvolvida faz parte de uma pesquisa em desenvolvimento, que analisa a apropaiação de memes de internet como estratégia discursiva no campo religioso. A intenção do artigo foi fazer uma reflexão teórica preliminar com vistas a aprofundar como a religião pode ser tomada como objeto de estudo comunicacional e que interfaces são possíveis. Assim como certamente ocorrerá com a referida pesquisa, à medida em que se desenvolvem estudos voltados a diferentes objetos do mesmo campo, vão se descortinando também indícios sobre o que é específico da religião quanto ao comunicacional, através da identificação dos diferentes modos como fiéis e grupos religiosos atuam na dinâmica da midiatização e, em seu contexto, desenvolvem novas interações.

Comun. \& Inf., Goiânia, GO, v. 19, n. 2, p. 71-85, jul./dez. 2016. 


\section{REFERÊNCIAS}

ARMSTRONG, Karen. Uma história de Deus: quatro milênios de busca do judaísmo, cristianismo e islamismo. São Paulo: Companhia das Letras, 1994.

BORELLI, Viviane (org.). Mídia e religião: entre o mundo da fé e o do fiel. Rio de Janeiro: EPapers, 2010.

BOURDIEU, Pierre. O Poder Simbólico. Rio de Janeiro: Bertrand Brasil, 2012.

BRAGA, José Luiz. Constituição do campo da comunicação. Verso e Reverso, São Leopoldo, RS, vol. 25, n.58, p.62-77, jan/abr. 2011. Disponível em:

$<$ http://revistas.unisinos.br/index.php/versoereverso/article/view/924>. Acesso em: 22 Jul 2015.

BRAGA, José Luiz. Mediatização como processo interacional de referência. Animus, Santa Maria, RS, vol. 5, n.2, p.9-35, jul/dez. 2006.

FAUSTO NETO, Antonio. Fragmentos de uma "analítica" da midiatização. Matrizes, São Paulo, vol.1, n.2, p. 89-105, abr. 2008. Disponível em:

$<$ http://www.matrizes.usp.br/index.php/matrizes/article/view/88>. Acesso em 22 Jul 2015.

FRANÇA, Vera Veiga. O objeto da comunicação: a comunicação como objeto. In: HOHLFELDT, A.; MARTINO, L.; FRANÇA, V. Teorias da comunicação. Petrópolis, RJ: Vozes, 2001.

MARTINO, Luiz C. Interdisciplinaridade e objeto de estudo da comunicação. In: HOHLFELDT, A.; MARTINO, L.; FRANÇA, V. Teorias da comunicação. Petrópolis, RJ: Vozes, 2001.

MARTINO, Luis Mauro Sa. A pesquisa em mídia e religião no Brasil: articulações teóricas na formação de uma área de estudos. Comunicação \& Inovação, São Caetano do Sul, SP, v. 15, n. 29, p. 81-93, jul/dez. 2014. Disponível em:

$<$ http://seer.uscs.edu.br/index.php/revista_comunicacao_inovacao/article/view/2791>. Aceso em: 22 Jul 2015.

RODRIGUES, Adriano Duarte. Experiência, modernidade e campo dos media. Biblioteca On Line de de Ciências da Comunicação. Portugal, 1999. Disponível em:

$<$ http://www.bocc.ubi.pt/pag/rodrigues-adriano-expcampmedia.pdf $>$. Acesso em 22 Jul 2015.

SIGNATES, Luiz. O que é especificamente comunicacional nos estudos brasileiros de comunicação da atualidade? In: BRAGA, J. L.; FERREIRA, J. ; FAUSTO NETO, A.; GOMES, P. G. (orgs.).

Dez perguntas para a produção de conhecimento em comunicação. São Leopoldo, RS: Ed. Unisinos, 2013.

SILVERSTONE, Roger. Por que estudar a mídia? São Paulo: Edições Loyola, 2002.

VERÓN, Eliseo. Teoria da midiatização: uma perspectiva semioantropológica e algumas de suas consequências. Matrizes, São Paulo, v. 8, n. 1, p. 13-19, jan/jun. 2014. Disponível em:

$<$ http://www.matrizes.usp.br/index.php/matrizes/article/view/561>. Acesso em: 22 Jul 2015.

VERÓN, Eliseo. Fragmentos de um tecido. São Leopoldo, RS, Editora Unisinos, 2004. 
WEBER, Max. A ética protestante e o espírito do capitalismo. São Paulo: Pioneira, 1996.

Recebido em: 23/07/2015

Aceito em: 11/10/2015

Publicado em: 31/12/2016

Comun. \& Inf., Goiânia, GO, v. 19, n. 2, p. 71-85, jul./dez. 2016. 